\title{
Gaucher disease type 1
}

INSERM

\section{Source}

INSERM. (1999). Orphanet: an online rare disease and orphan drug data base. Gaucher disease type 1. ORPHA:77259

Gaucher disease type 1 is the chronic non-neurological form of Gaucher disease (GD; see this term) characterized by organomegaly, bone involvement and cytopenia. 